\title{
Índices fisiológicos e de crescimento de um porta-enxerto de aceroleira sob estresse salino
}

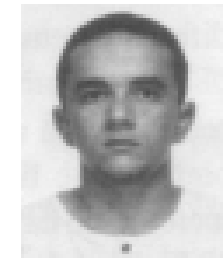

\author{
Marcelo T. Gurgel ${ }^{1}$, Pedro D. Fernandes ${ }^{2}$, Hans R. Gheyi², Francisco J. de S. Santos ${ }^{3}$, \\ Idelfonso L. Bezerra ${ }^{4} \&$ Reginaldo G. Nobre ${ }^{4}$
}

\begin{abstract}
1 DEAg/CCT/UFCG. CP 10087, CEP 58.109-970, Campina Grande, PB. E-mail: mtgurgel@bol.com.br (Foto)
2 DEAg/CCT/UFCG. Fone: (83) 310-1185. E-mail: pdantas@deag.ufcg.edu.br e hans@deag.ufcg.edu.br

${ }^{3}$ EMBRAPA Meio Norte. CP 341, CEP 64.200-970, Parnaíba, PI. Fone: (86) 315-1200. E-mail: fjseixassantos@ig.com.br

${ }^{4}$ DEAg/CCT/UFCG. Campina Grande, PB. E-mail: idelfonsolb@bol.com.br e rgnobre@bol.com.br
\end{abstract}

Protocolo 75 - 2/5/2003 - Aprovado em 22/10/2003

\begin{abstract}
Resumo: Na literatura há registros de variações na fisiologia e no desenvolvimento de genótipos diversos em condições de estresse salino. Não se encontrando informações nesse sentido, sobre aceroleira, conduziu-se este trabalho com o objetivo de se avaliar os efeitos da salinidade sobre o clone BV1, através de variáveis fisiológicas e de crescimento, na fase de formação de portaenxerto. Os estudos foram realizados no Campo Experimental de Pacajus (EMBRAPA), na cidade de Pacajus, $C E$, testando-se seis níveis de salinidade da água de irrigação (condutividade elétrica, variando de 0,5 a 5,5 dS $\mathrm{m}^{-1}$ ), preparada mantendo-se a proporção 7:2:1 entre $\mathrm{Na}: \mathrm{Ca}: \mathrm{Mg}$, respectivamente. $\mathrm{O}$ sistema radicular da aceroleira é mais sensível à salinidade que a parte aérea, assim como a fitomassa seca total quando comparada com a área foliar. A eficiência da aceroleira em produzir matéria nova por unidade de matéria preexistente, aumenta com a elevação do nível de salinidade da água de irrigação. A velocidade de crescimento e a fotossíntese líquida da aceroleira decrescem com o aumento do estresse salino.
\end{abstract}

Palavras-chave: Malpighia emaginata, desenvolvimento, salinidade

\section{Physiological and growth indices of a West Indian Cherry rootstock under saline stress}

\begin{abstract}
It is known that the physiological behavior of the plants under saline stress conditions vary among genotypes. Considering non existence of references about effect of salinity in West Indian Cherry plants, the objective of this study was to evaluate such effects on the growth and physiology of the clone BV1 rootstock. The studies were carried out at the Experimental Center of Pacajus (EMBRAPA), in the city of Pacajus - CE. The treatments studied were six levels of salinity of the irrigation water (electrical conductivity varying from 0.5 to $5.5 \mathrm{dS} \mathrm{m}^{-1}$ ). The results obtained show that the efficiency of the West Indian Cherry to produce new matter in relation to preexisting increases with the elevation of salinity. The root system of the West Indian Cherry is more affected than the aerial parts by water salinity. The growth velocity and the net photosynthesis assimilation rate of the West Indian Cherry were found to reduce with increase in irrigation water salinity.
\end{abstract}

Key words: Malpighia emaginata, development, salinity

\section{INTRODUÇÃO}

O Brasil, com uma área superior a dois milhões de hectares plantados com fruteiras, já foi o maior produtor mundial de frutas ocupando, atualmente, o segundo lugar. Embora produza mais de 30 milhões de toneladas de frutas e fature, anualmente, cerca de 60 milhões de dólares com exportações, este país ocupa a modesta classificação de $90^{\circ}$ lugar no contexto mundial dos exportadores (Bandeira et al., 1998).

Nas últimas décadas, a fruticultura irrigada é uma das atividades agrícolas com maior crescimento no Nordeste, constituindo-se em um dos principais vetores para o desenvolvimento econômico da região, principalmente de suas áreas semi-áridas. Dentre os principais cultivos frutícolas destaca-se o de acerola, com grandes perspectivas de expansão em virtude das condições favoráveis de temperatura e luminosidade à sua exploração (Alves, 1989).

Por sua riqueza em vitamina $\mathrm{C}$, a acerola é, hoje, em termos relativos, uma das principais culturas de exportação da fruticultura brasileira. Está sendo consumida de forma crescente por japoneses, europeus e norte-americanos (Lucas, 1993). O uso de irrigação implica necessariamente na incorporação 
gradativa de sais no solo, sobretudo na zona radicular (Yeo, 1999; Wang et al., 2002), com reflexos sobre o crescimento e desenvolvimento vegetal; as consequiências sobre as plantas são estresse hídrico, problemas de toxicidade iônica e de desordem nutricional (Shannon, 1997; Cushman, 2001). O estresse salino, segundo Hassanein (1999), representa um dos mais sérios fatores ambientais a limitar o crescimento e a produção das culturas, induzindo a modificações morfológicas, estruturais e metabólicas.

As culturas respondem diferenciadamente à salinidade, algumas com rendimentos aceitáveis em condições de elevada condutividade elétrica do solo ou da água de irrigação, enquanto outras são sensíveis em níveis relativamente baixos. A diferença se deve à maior capacidade de adaptação osmótica de algumas espécies, as quais absorvem água em um nível compatível com o nível celular, mesmo em condições de alta salinidade. Essa capacidade de adaptação permite a seleção de genótipos mais tolerantes e capazes de produzir rendimentos economicamente aceitáveis, mesmo quando não se consegue manter a salinidade do solo abaixo do nível de tolerância da maioria das plantas (Marcum, 2001).

Enquanto na literatura se encontram informações sobre os níveis de tolerância à salinidade de algumas fruteiras tropicais, dentre elas bananeira (Santos, 1997), coqueiro (Ferreira Neto et al., 2002) e cajueiro (Bezerra et al., 2002) sobre a aceroleira não há dados disponíveis. Assim, com este trabalho objetivouse estudar o crescimento e o desenvolvimento de um portaenxerto de aceroleira, quando submetido a diferentes níveis de salinidade da água de irrigação, avaliando-se os seus efeitos sobre variáveis fisiológicas e de crescimento.

\section{MATERIAL E MÉTODOS}

O experimento foi conduzido em instalações da EMBRAPA Agroindústria Tropical, localizadas no Campo Experimental de Pacajus (CEP), Estado do Ceará, no período de fevereiro a maio de 2001.

Na irrigação foram utilizadas águas de diferentes níveis de salinidade $\left(0,5,1,5,2,5,3,5,4,5 \mathrm{e} 5,5 \mathrm{dS} \mathrm{m}^{-1}\right.$ caracterizados de $\mathrm{S}_{1}$ $\mathrm{a} \mathrm{S}_{6}$, respectivamente) sobre o crescimento de um porta-enxerto de aceroleira (clone BV1). As águas foram preparadas a partir de soluções $1 \mathrm{~N} \mathrm{de} \mathrm{NaCl}, \mathrm{CaCl}_{2} .2 \mathrm{H}_{2} \mathrm{O}$ e $\mathrm{MgCl}_{2} .6 \mathrm{H}_{2} \mathrm{O}$, utilizandose água de poço do CEP (condutividade elétrica $\mathrm{CE}_{\mathrm{a}}=0,5$ $\mathrm{dS} \mathrm{m}^{-1}$ ), mantendo-se equivalente proporção de 7:2:1 entre $\mathrm{Na}: \mathrm{Ca}: \mathrm{Mg}$, respectivamente, comum em águas encontradas na região (Medeiros, 1992). Os tratamentos foram distribuídos em blocos casualizados, com 4 repetições, sendo a parcela constituída por 54 plantas. Uma mistura de casca de arroz carbonizada, palha de carnaúba triturada e húmus (proporção de 2:1:1), foi utilizada como substrato (Chaves et al., 2000). Previamente à instalação do experimento, realizou-se análise do substrato, cujas características químicas, determinadas de acordo com metodologias recomendadas pela EMBRAPA (1997), constam na Tabela 1.

Os recipientes utilizados foram tubetes plásticos $(19 \mathrm{~cm}$ de altura e $6,3 \mathrm{~cm}$ de diâmetro), com capacidade para $288 \mathrm{~mL}$ e abertura na parte inferior para permitir livre drenagem. Os recipientes foram dispostos em bandejas com capacidade para
Tabela 1. Características químicas do substrato utilizado no experimento

\begin{tabular}{|c|c|}
\hline Características Químicas & Valor \\
\hline \multicolumn{2}{|l|}{ Complexo sortivo $\mathrm{mmoL}_{\mathrm{c}} \mathrm{dm}^{-3}$} \\
\hline Cálcio & 88,86 \\
\hline Magnésio & 40,80 \\
\hline Sódio & 130,00 \\
\hline Potássio & 34,00 \\
\hline Hidrogênio + Alumínio (Ac. Potencial) & 26,00 \\
\hline Soma de bases $(\mathrm{S})$ & 293,66 \\
\hline Capacidade de troca de cátions (CTC) & 319,66 \\
\hline Saturação de bases (V) - \% & 91,97 \\
\hline Percentagem de sódio trocável (PST) & 40,67 \\
\hline Matéria orgânica $\left(\mathrm{g} \mathrm{dm}^{-3}\right)$ & 215,40 \\
\hline Fósforo (resina) (mg dm ${ }^{-3}$ ) & 48,87 \\
\hline Manganês $\left(\mathrm{mg} \mathrm{dm}^{-3}\right)$ & 5,40 \\
\hline Zinco $\left(\mathrm{mg} \mathrm{dm}^{-3}\right)$ & 293,66 \\
\hline Cobre $\left(\mathrm{mg} \mathrm{dm}^{-3}\right)$ & 4,41 \\
\hline Ferro $\left(\mathrm{mg} \mathrm{dm}^{-3}\right)$ & 19,20 \\
\hline Condutividade elétrica do extrato de saturação $\left(\mathrm{dS} \mathrm{m}^{-1}\right)$ & 5,30 \\
\hline
\end{tabular}

54 unidades, as quais ficavam apoiadas em bancadas metálicas (cantoneiras), a uma altura de $0,8 \mathrm{~m}$ do solo. Após o enchimento dos tubetes e acondicionamento nas bandejas, procedeu-se a 8 lavagens sucessivas, com $2 \mathrm{~L}$ da água do poço $\left(0,5 \mathrm{dS} \mathrm{m}^{-1}\right)$, em cada aplicação, de forma a reduzir a salinidade natural do substrato. No semeio utilizaram-se cinco sementes por tubete, a uma profundidade de aproximadamente $2 \mathrm{~cm}$, conforme procedimento do Campo Experimental de Pacajus (CEP).

As irrigações com água de diferentes valores de $\mathrm{CE}_{\mathrm{a}}$, foram efetuadas diariamente, em uma única aplicação, ao final da tarde. No cálculo do volume aplicado foi prevista uma fração de lixiviação de $40 \%$, de forma a não haver acumulação de sais no substrato. Os demais tratos culturais, como desbaste, repicagem, controle de ervas daninhas, adubação e tratos fitossanitários, seguiram os procedimentos empregados no CEP.

Aos 50 e 90 dias após a emergência (DAE) da primeira plântula, utilizando-se de 16 plantas por tratamento (4 por repetição), avaliaram-se: área foliar (AF); relação raiz/parte aérea $\left(\mathrm{R} / \mathrm{PA}=\mathrm{F}_{\mathrm{R}} / \mathrm{F}_{\mathrm{PA}}\right.$, em g g $\left.{ }^{-1}\right)$ de acordo com Magalhães (1979) e teor de água na folha $\left(\mathrm{TAF}=\left[\left(\mathrm{PF}_{\mathrm{f}}-\mathrm{PS}_{\mathrm{f}}\right) / \mathrm{PF}_{\mathrm{f}}\right] \mathrm{x} 100\right)$ e no caule $\left(\mathrm{TAC}=\left[\left(\mathrm{PF}_{\mathrm{c}}-\mathrm{PS}_{\mathrm{c}}\right) / \mathrm{PF}_{\mathrm{c}}\right] \times 100\right)$. Houve avaliação, ainda, da taxa de crescimento absoluto $\left(\mathrm{TCA}=\left(\mathrm{P}_{2}-\mathrm{P}_{1}\right) /\left(\mathrm{t}_{2}-\mathrm{t}_{1}\right), \mathrm{em} \mathrm{mg} \mathrm{dia}{ }^{-1}\right)$, taxa de crescimento relativo $\left(\mathrm{TCR}=\mathrm{TCA} / \mathrm{FS}_{\mathrm{T}}, \mathrm{em} \mathrm{mg} \mathrm{mg}^{-1} \mathrm{dia}^{-1}\right.$ ), taxa de assimilação líquida (TAL $=\mathrm{TCA} / \mathrm{RAF}, \mathrm{em} \mathrm{mg} \mathrm{cm} \mathrm{dia}^{-1}$ ) e razão de área foliar $\left(\mathrm{RAF}=\mathrm{AF} / \mathrm{FS}_{\mathrm{T}}, \mathrm{em} \mathrm{cm}^{2} \mathrm{~g}^{-1}\right)$, a partir dos modelos propostos por Cairo (1995) e Benincasa (1988), em que $\mathrm{F}_{\mathrm{R}}$ e $\mathrm{F}_{\mathrm{PA}}$ são fitomassa seca da raiz e da parte aérea $(\mathrm{g}) ; \mathrm{PF}_{\mathrm{f}}$ e $\mathrm{PS}_{\mathrm{f}}$ são peso fresco e seco das folhas no tempo $\mathrm{t}(\mathrm{g}) ; \mathrm{PF}_{\mathrm{c}} \mathrm{e}$ $\mathrm{PS}_{\mathrm{c}}$ - peso fresco e seco do caule no tempo $\mathrm{t}(\mathrm{g}) ; \mathrm{P}_{1}$ e $\mathrm{P}_{2}$ - peso da matéria seca total no tempo $t_{1}$ e no tempo $t_{2}$, respectivamente; $\mathrm{AF}$ é área foliar $\left(\mathrm{cm}^{2}\right)$ e $\mathrm{FS}_{\mathrm{T}}$ é a fitomassa seca total $(\mathrm{g})$.

A área foliar das plantas foi determinada com auxílio de um medidor eletrônico (modelo "LI - 3000A"). Para obtenção dos dados de fitomassa seca, o material vegetal foi secado em estufa, com ventilação forçada de ar, a $65^{\circ} \mathrm{C}$, até peso constante. Os dados médios obtidos foram comparados pelo teste "F" e análise de regressão, de acordo com Ferreira (2000). 


\section{RESULTADOS E DISCUSSÃO}

\section{Área foliar, relação raiz/parte área e razão de área foliar}

Foram detectados efeitos significativos da salinidade da água sobre a área foliar (AF), relação raiz/parte aérea (R/PA) e razão de área foliar (RAF), nas avaliações realizadas aos 50 e 90 dias após a emergência (DAE) da primeira plântula (Figura 1).

A área foliar foi afetada negativamente (modelo quadrático) pela salinidade, aos 50 DAE $(\mathrm{p}<0,01)$, com decrementos
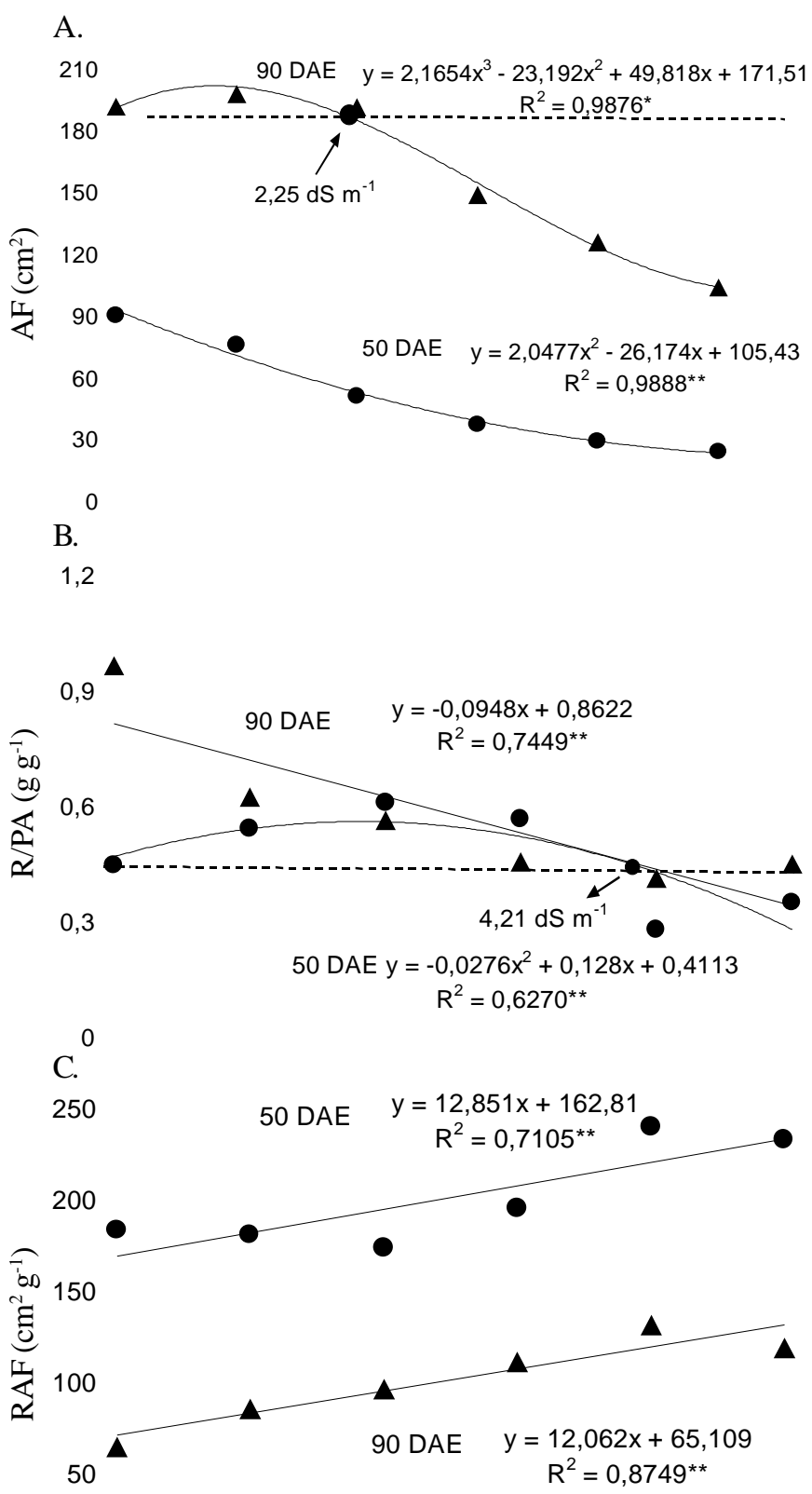

0

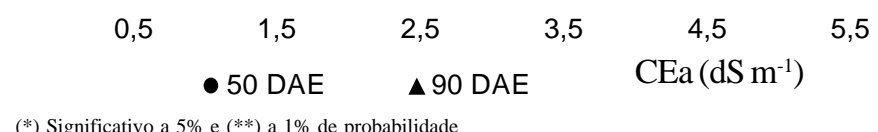

Figura 1. Área foliar (AF), relação raiz/parte aérea (R/PA) e razão de área foliar (RAF) da aceroleira, aos 50 e 90 dias após a emergência (DAE) da primeira plântula, em função da salinidade da água de irrigação relativos (comparado a $S_{1}$ ) de 23,78, 43,14, 58,10, 68,65 e 74,79\%, para $\mathrm{S}_{2}, \mathrm{~S}_{3}, \mathrm{~S}_{4}, \mathrm{~S}_{5}$ e $\mathrm{S}_{6}$, respectivamente (Figura $1 \mathrm{~A}$ ). Aos 90 DAE, os dados se ajustaram ao modelo cúbico ( $p<0,05)$, com incremento positivo em relação ao $\mathrm{S}_{1}$, até CEa de $2,25 \mathrm{dS} \mathrm{m}^{-1}$, a partir do qual a AF decresceu 19,00, 35,37 e 45,40\%, em S, $\mathrm{S}_{5}$ e $\mathrm{S}_{6}$, respectivamente. A área foliar foi mais afetada aos $50 \mathrm{DAE}$ quando decresceu $74,79 \%$, comparados com $45,40 \%$ aos 90 DAE, no nível mais elevado de salinidade $\left(\mathrm{S}_{6}-5,5 \mathrm{dS} \mathrm{m}^{-1}\right)$; ocorreu, portanto, uma adaptação da aceroleira ao estresse salino, ao longo do tempo. Em clones de cajueiro anão-precoce sob condições de salinidade, Carneiro et al. (2002) obtiveram dados semelhantes, com menor efeito depressivo da salinidade sobre a AF aos 100 dias que aos 50 dias após o plantio.

A relação raiz/parte aérea (Figura 1B) foi afetada significativamente pela salinidade $(\mathrm{p}<0,01)$ nas duas épocas de avaliação (50 e 90 DAE), sendo quadrática e linear a equação obtida em cada fase, respectivamente. Na primeira avaliação (50 DAE), ocorreu incremento de R/PA até o nível de 4,21 dS m${ }^{-1}$ (comparado a $S_{1}$ ), com posteriores decréscimos de 8,54 e $40,14 \%$ nos tratamentos $\mathrm{S}_{5}$ e $\mathrm{S}_{6}$, respectivamente. Aos 90 DAE o decremento relativo foi de $11,63 \%$ por aumento unitário da CEa.

De modo geral, $\mathrm{a}$ R/PA decresceu à medida que se elevaram os níveis de salinidade, em razão da raiz ter sido mais afetada pelos tratamentos nas duas épocas consideradas. Nobre (2002) encontrou resultados diferentes em um porta-enxerto de gravioleira, sendo mais afetado o crescimento da parte aérea que o da raiz, em condições de salinidade. Conforme Morales et al. (2001), nem todas as partes da planta são igualmente afetadas pela salinidade, bem como a adaptação ao estresse salino varia entre espécies e em um mesmo genótipo pode variar entre estádios fenológicos (Amor et al., 2001).

Quanto à razão de área foliar (RAF) (Figura 1C), ocorreu incremento linear significativo ( $\mathrm{p}<0,01$ ), de 7,59 e 16,96\%, aos 50 e 90 DAE, respectivamente, para cada aumento unitário da CEa (relativo a $\mathrm{S}_{1}$ ). Os dados crescentes de RAF nas duas épocas sugerem um efeito menor da salinidade sobre a área foliar (AF), quando relacionada com a fitomassa seca total (FST). Com o tempo (entre 50 e 90 DAE), o impacto da salinidade sobre a RAF foi reduzido, fato também observado por Bezerra (2001) em mudas enxertadas de cajueiro anão-precoce, em condições de salinidade.

\section{Teor de água}

Ocorreram incrementos em TAF e TAC (comparados com $\mathrm{S}_{1}$ ) de 1,53 e 2,78\% (Figura 2A e B), respectivamente, para cada aumento unitário de CEa. Percebe-se menor acúmulo de água no caule $(79,68 \%)$, que nas folhas $(83,34 \%)$, no maior nível de salinidade $\left(5,5 \mathrm{dS} \mathrm{m}^{-1}\right)$. Carneiro et al. (2002) verificaram tendência semelhante com o TAF em clones de cajueiro anãoprecoce, aos 50 e 100 dias após o plantio, sob diferentes condições de salinidade.

$\mathrm{O}$ aumento do teor de água em folhas e caule com o aumento da salinidade da água de irrigação, pode ser reflexo do ajustamento osmótico, acumulando a planta íons no vacúolo das células ou sintetizando compostos orgânicos para baixar o potencial hídrico interno e garantir a absorção de água, mantendo a turgescência das células; contudo, é importante ressaltar que, devido ao aumento da concentração de solutos 


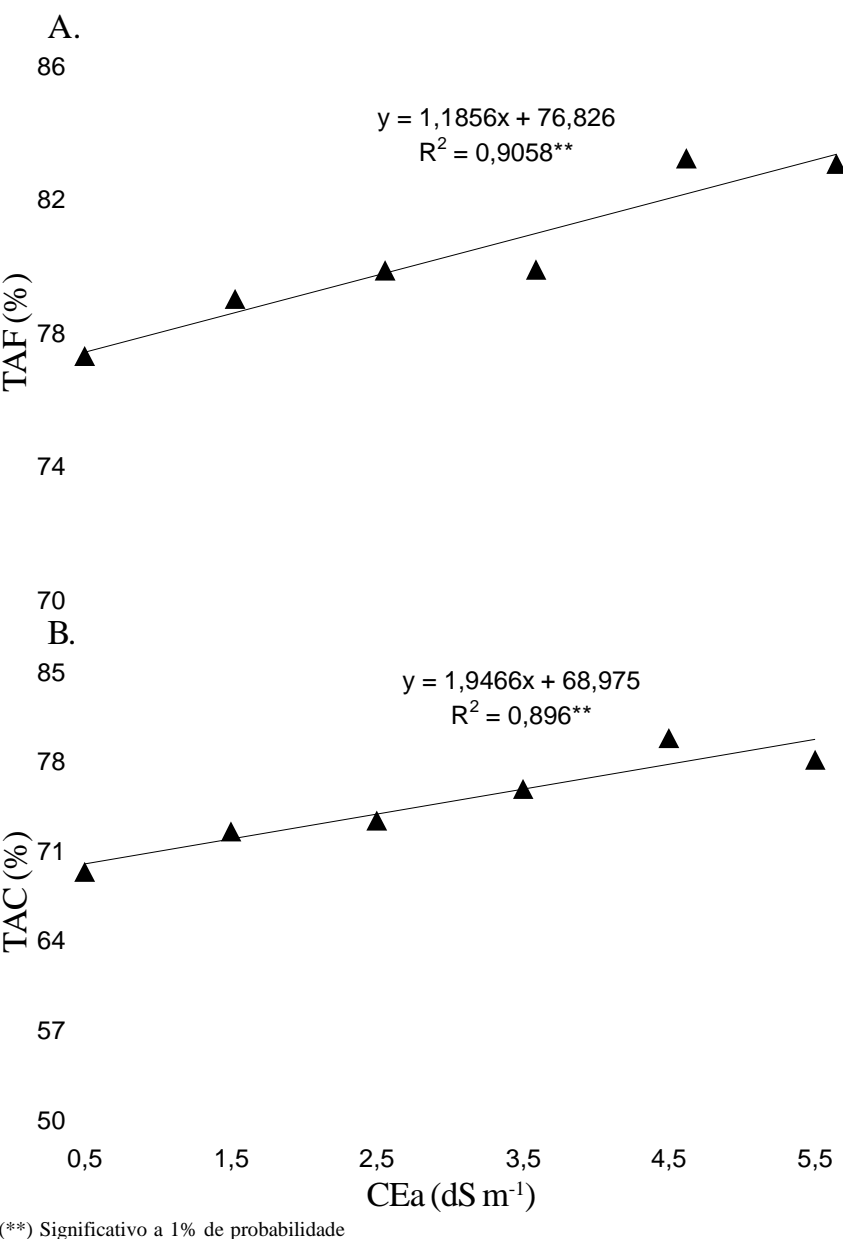

Figura 2. Teor de água da folha - TAF (A) e do caule - TAC (B), 90 dias após a emergência (DAE) da primeira plântula de aceroleira, em função da salinidade da água de irrigação

osmoticamente ativos, a água no interior das células, embora em maior quantidade, passa a ser cada vez menos disponível para realizar trabalho, com conseqüências negativas sobre a planta (Cushman, 2001).

\section{Crescimento e assimilação líquida}

As taxas de crescimento absoluto (TCA), relativo (TCR) e de assimilação líquida (TAL), no período de 50 a 90 DAE (Figura 3 ), foram afetadas significativamente pela salinidade ( $p<0,01)$.

$\mathrm{O}$ crescimento absoluto (TCA) das plantas decresceu com os tratamentos salinos, seguindo um modelo quadrático (Figura 3A). Os decréscimos relativos da TCA, no intervalo de $50-90$ DAE, comparados com $\mathrm{S}_{1}$, foram de 22,09, 40,29, 54,57, 64,95 e $71,42 \%, \mathrm{em} \mathrm{S}_{2}, \mathrm{~S}_{3} \mathrm{~S}_{4}, \mathrm{~S}_{5}$ e $\mathrm{S}_{6}$, respectivamente. De acordo com Cushman (2001), na medida em que a concentração salina do solo aumenta acima de um limite tolerável, a taxa de crescimento da maioria das espécies vegetais diminui progressivamente. Em outras espécies frutíferas foram encontrados, também, efeitos negativos da salinidade sobre a TCA das plantas, como no caso de cajueiro anão-precoce (Carneiro, 2001) e de gravioleira (Nobre, 2002).

No tocante à taxa de crescimento relativo (TCR), houve efeito linear da salinidade (Figura 3B), com incremento de $12,76 \%$ para cada incremento unitário da $\mathrm{CEa}$, em relação a $\mathrm{S}_{1}$, chegando a $63,78 \%$ no nível mais elevado $\left(\mathrm{S}_{6}\right)$. Por esses dados, considera-se que o clone BV1 de aceroleira teve, no intervalo de tempo estudado (40 dias), boa eficiência em produzir material novo - novos produtos fotossintéticos por material preexistente, refletindo-se numa tolerância maior das plantas ao final do período de estudo.

Dados semelhantes foram encontrados por Campos (2001) em tomate, tipo industrial, e por Viana (2000) em alface, ambos trabalhando em condições de estresse salino. Ao contrário, Carneiro (2001), avaliando a influência de diferentes níveis de salinidade da água de irrigação (CEa de 0,$7 ; 1,4 ; 2,1$ e 2,8 dS m ${ }^{-1}$ ) sobre a TCR de clones de cajueiro anão-precoce, na fase de produção de mudas, não constatou qualquer efeito sobre a
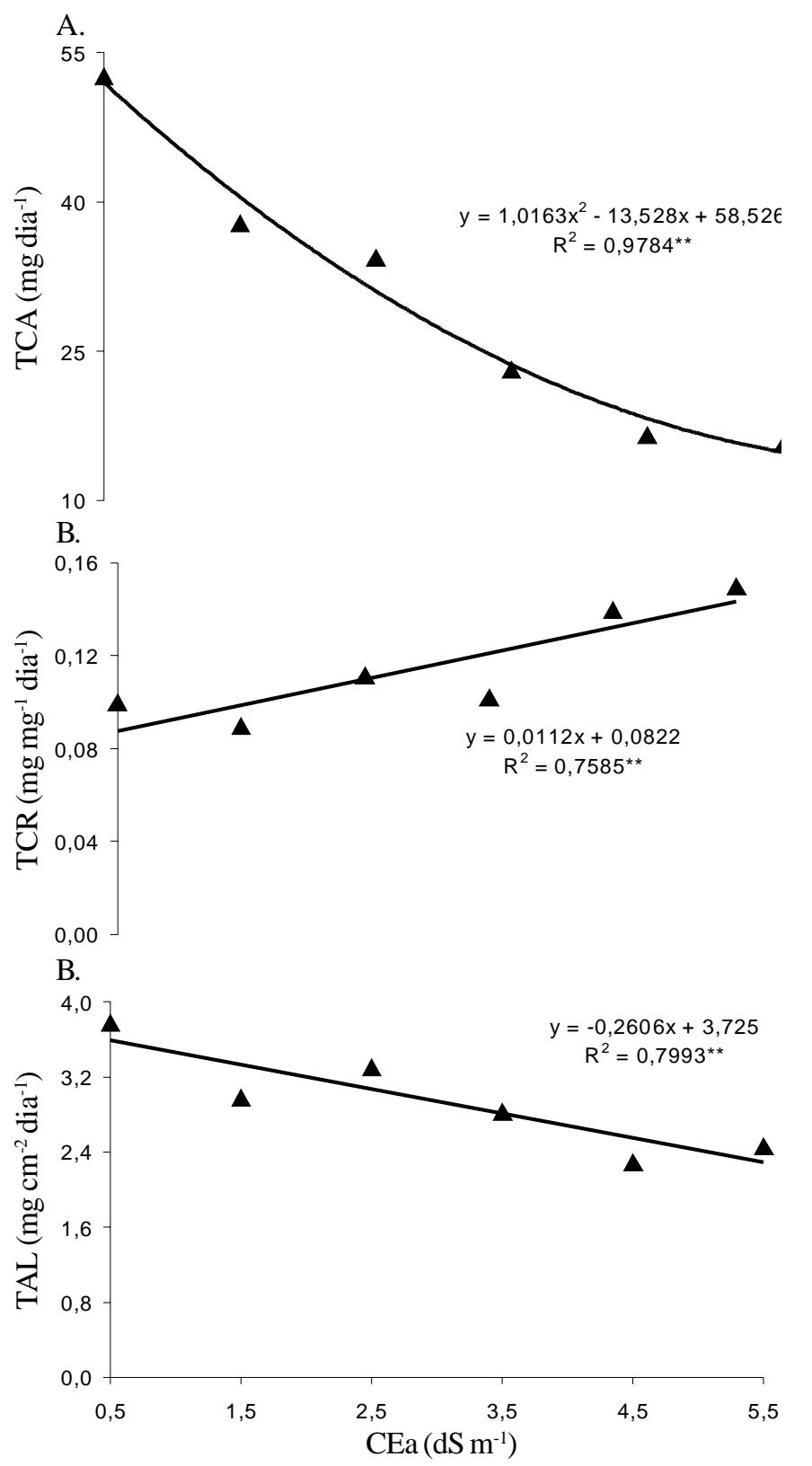

(**) Significativo a a $1 \%$ de probabilidade

Figura 3. Taxas de crescimento absoluto - TCA (A), relativo TCR (B) e de assimilação líquida - TAL (C) da aceroleira no período de 50 a 90 dias após a emergência (DAE) da primeira plântula, em função da salinidade da água de irrigação 
eficiência da cultura em produzir matéria nova por unidade de matéria preexistente no período de avaliação (50 a 100 dias após o plantio).

A taxa de assimilação líquida (TAL), no período de 50 a 90 DAE, decresceu linearmente, 7,25\% por aumento unitário da $\mathrm{CEa}$, em relação a $\mathrm{S}_{1}$ (Figura 3C). Portanto, a salinidade afetou a taxa de fotossíntese líquida ao longo do período de observação, em relação à matéria seca produzida por unidade de área foliar ( $\mathrm{p}<0,01)$. De acordo com Benincasa (1988), em média cerca de $90 \%$ da matéria seca acumulada pelas plantas, ao longo do seu crescimento, resultam de atividade fotossintética.

Em termos relativos, os valores de TCR e TAL obtidos em $\mathrm{S}_{1}\left(\mathrm{CEa}=0,5 \mathrm{dS} \mathrm{m}^{-1}\right)$, comparados com os de $\mathrm{S}_{6}\left(\mathrm{CEa}=5,5 \mathrm{dS} \mathrm{m}^{-1}\right)$, aumentaram e diminuíram em 63,78 e $36,25 \%$, respectivamente; portanto, apesar da salinidade ter afetado a taxa de assimilação líquida houve, no final do período de estudo, um saldo positivo de produção de fotoassimilados por unidade de matéria preexistente, indicando aumento de tolerância do genótipo BV1 de acerola, entre 50 e 90 DAE. Resultados semelhantes foram relatados por Azevedo Neto \& Tabosa (2000), estudando o efeito de estresse salino sobre o crescimento de plântulas de milho, ao observarem ser a produção de matéria seca mais afetada pelo estresse salino que a fotossíntese líquida (TAL). Entretanto, em plantas de tomate sob estresse salino, Alarcon et al. (1994) não encontraram alterações significativas na TAL. Esses autores ponderam que a taxa de expansão celular parece ser afetada mais rapidamente que a taxa fotossintética, em condições de salinidade, o que indiretamente foi verificado neste trabalho, ao se constatar maiores decréscimos dos valores de fitomassa que da taxa de assimilação líquida.

Silva (2002), testando níveis de salinidade da água de irrigação semelhantes aos do presente trabalho, em portaenxertos de mangueira, não verificou efeito significativo da CEa sobre TCA, TCR e TAL em avaliações realizadas aos 30, 40 e 60 dias após o semeio.

\section{CONCLUSÕES}

1. A salinidade da água de irrigação na aceloreira prejudica mais o sistema radicular que a parte aérea e esta última é menos afetada que a fitomassa seca total.

2. A folha acumula mais água que o caule à medida que se elevam os níveis de salinidade da água de irrigação.

3. Aumentando a salinidade da água de irrigação, aumenta também a eficiência da aceroleira em produzir matéria nova por unidade de matéria preexistente.

4. A capacidade da planta em produzir fotoassimilados é menos afetada que as taxas de crescimento.

5. A tolerância da aceroleira à salinidade aumenta com a idade na fase de formação do porta-enxerto.

\section{LITERATURA CITADA}

Alarcon, J.J.; Sanchz-Blanco, M.J.; Boalrin, M. C.; Torrecillas, A. Growth and osmotic adjustment of two tomato cultivars during and after saline stress. Plant and Soil, Dordrecht, v.166, p.75-82, 1994.
Alves, R.E. Contribuição ao estudo da acerola (Malpighia glabra L.): propagação assexuada e teores de nutrientes. Areia: UFPB, 1989, 79p. Monografia Graduação

Amor, F.M.; Martinez, V.; Cerda, A. Salt tolerance of tomato plants as affected by stage of plant development. Hortscience, Alexandria, v.36, n.7, p.1260-1263, 2001.

Azevedo Neto, A.D. de; Tabosa, J.N. Estresse salino em plântulas de milho: Parte II - distribuição dos macronutrientes catiônicos e suas relações com sódio. Revista Brasileira de Engenharia Agrícola e Ambiental, Campina Grande: v.4, n.2, p.165-171, 2000.

Bandeira, C.T.; Miranda, F.R. de; Braga Sobrinho, R.; Cardoso, J.E. Produção de dois clones de acerola (Malpighia glabra L.) sob diferentes regimes de irrigação. Fortaleza: EMBRAPA, 1998, 5p.

Benincasa, M.M.P. Análise de crescimento de plantas. Jaboticabal: FUNEP, 1988. 42p.

Bezerra, I.L. Produção de mudas de cajueiro anão-precoce, usando água de diferentes salinidades. Campina Grande, 2001, 85p. Dissertação Mestrado

Bezerra, I.L.; Gheyi, H.R.; Fernandes, P.D.; Santos, F.J. de S.; Gurgel, M.T.; Nobre, R.G. Germinação, formação de portaenxerto e enxertia de cajueiro anão-precoce, sob estresse salino. Revista Brasileira de Engenharia Agrícola e Ambiental, Campina Grande, v.5, n.3, p.420-424, 2002.

Cairo, P.A.R. Curso básico de relações hídricas de plantas. Vitória da Conquista: UESB, 1995. 32p.

Campos, C.A.B. Germinação, desenvolvimento e produção de tomate tipo industrial, sob estresse salino. Campina Grande, 2001. 149p. Dissertação Mestrado

Carneiro, P.T. Germinação e desenvolvimento inicial de clones de cajueiro anão-precoce sob condições de salinidade. Campina Grande, 2001. 85p. Dissertação Mestrado

Carneiro, P.T.; Fernandes, P.D.; Gheyi, H.R.; Soares, F.A.L. Germinação e crescimento inicial de genótipos de cajueiro anão-precoce em condições de salinidade. Revista Brasileira de Engenharia Agrícola e Ambiental, Campina Grande, v.6, n.2, p.199-206, 2002.

Chaves, J.C.M.; Cavalcante Jr., A.T.; Correia, D.; Souza, F.X. de; Araújo, C.A.T. Normas de produção de mudas. Fortaleza: Embrapa Agroindústria Tropical, 2000.37p. Documento, 41

Cushman, J.C. Osmoregulation in plants: implications for agriculture. American Zoologist, New York, v.41, n.4, p.758769, 2001.

EMBRAPA - Empresa Brasileira de Pesquisa Agropecuária. Manual de métodos de análise de solo. Centro Nacional de Pesquisa de Solos. 2. ed. Rev.atual. Rio de Janeiro, 1997. 212p. EMBRAPA-CNPS. Documento, 1

Ferreira, P.V. Estatística experimental aplicada à agronomia. Maceió: UFAL; EDUFAL; FUNDEPES, 2000. 422p.

Ferreira Neto, M.; Gheyi, H.R.; Holanda, J.S. de; Medeiros, J.F. de.; Fernandes, P.D. Qualidade do fruto verde de coqueiro em função da irrigação com água salina. Revista Brasileira de Engenharia Agrícola e Ambiental, Campina Grande, v.6, n.1, p.69-75. 2002.

Hassanein, A.M. Alterations in protein and esterase patterns of peanut in response to salinity stress. Biologia Plantarum, Prague, v.42, n.2, p.241-248, 1999. 
Lucas, A. P. Acerola: suco da saúde conquista o mundo inteiro. Manchete Rural, Rio de Janeiro, v.5, n.69, p.10-13, 1993.

Magalhães, A.C.N. Análise quantitativa de crescimento. In: Ferri, M.G. (ed.). Fisiologia vegetal. São Paulo: EPU; EDUSP, 1979. p.331-350.

Marcum, K.B. Salinity tolerance of 35 bentgrass cultivars. Hortscience, Alexandria, v.36, n.2, p.374-376, 2001.

Medeiros, J.F. de. Qualidade da água de irrigação e evolução da salinidade nas propriedades assistidas pelo "GAT" nos Estados do RN, PB e CE. Campina Grande, 1992. 173p. Dissertação Mestrado

Morales, M.A.; Olmos, E.; Torrecillas, A.; Alarcon, J.J. Differences in water relations, leaf ion accumulation and excretion rates between cultivated and wild species of Limonium sp. grown in conditions of saline stress. Flora, Jena, v.196, n.5, p.345-352, 2001.

Nobre, R.G. Formação de mudas enxertadas de gravioleira em condições de salinidade. Campina Grande, 2002. 84p. Dissertação Mestrado
Santos, J.G.R. dos. Desenvolvimento e produção da bananeira nanica (Musa cavendishii) em diferentes condições de salinidade e lâminas de irrigação. Campina Grande/PB:UFPB, 1997. 146. Tese Doutorado

Shannon, M.C. Adaptation of plants to salinity. Advances in Agronomy, San Diego, v.60, p.75-120, 1997.

Silva, J.M. da. Germinação e desenvolvimento inicial de portaenxertos de mangueira sob condições de salinidade. Campina Grande: UFPB, 2002. 85p. Dissertação Mestrado

Viana, S.B.A. Estresse salino na germinação, fase de muda e produção de alface (Lactuca sativa L.). Campina Grande: UFPB, 2000. 127p. Dissertação Mestrado

Wang, D.; Wilson, C.; Shannon, M.C. Interpretation of salinity and irrigation effects on soybean canopy reflectance in visible and near-infrared spectrum domain. International Journal of Remote Sensing, Ottawa, v.23, n.5, p.811-824, 2002. Yeo, A. Predicting the interaction between the effects of salinity and climate change on crop plants. Scientia Horticulturae, Amsterdam, v.78, n.1, p.159-174, 1999. 